\title{
Hydrocarbon-soluble metal corrosion inhibitors. II. Physicochemical aspects of inhibitor action. Amides and salts of carboxylic acids
}

\author{
A. I. Altsybeeva, E. A. Tronova and V. V. Burlov \\ OOO NPO NEPhTEKhIM, ul. Pulkovskaya 10, St. Petersburg, 196158 Russian Federation \\ E-mail: altsybeeva@yandex.ru
}

\begin{abstract}
Some molecular aspects of protective action and specific behavior of hydrocarbon-soluble amides and salts of certain amines and morpholine with carboxylic acids in aqueousorganic environments are considered. The electron densities on those heteroatoms which are presumably responsible for adsorption and inhibition, as well as the Hansch $\pi$-constants have been calculated. Hypothetical adsorption models have been suggested for tridecanoic acid amides with hexylamine, cyclohexylamine, piperidine, piperazine, morpholine and the cyclohexylamine quaternary salt. Hypothetical adsorption schemes and the probable inhibitor efficiency of the products have been analyzed with consideration for data on the electronic charges and hydrophobicity of the molecules.
\end{abstract}

Key words: hydrocarbon-soluble corrosion inhibitors of metal corrosion; efficiency forecast; amides and salts of carboxylic acids; hexylamine; cyclohexylamine; morpholine; piperidine; piperazine.

Received: April 1, 2014.

doi: $\underline{10.17675 / 2305-6894-2014-3-3-160-166}$

In our previous paper [1], we considered the relationship between the physicochemical and electronic characteristics of inhibitors that allow one to forecast the efficiency of metal corrosion inhibitors in water-hydrocarbon media. We justified the necessity to develop a new domestic hydrocarbon-soluble multifunctional corrosion inhibitor that can find use not only in oil extraction and treatment but also in preservation of items in machine-building, bearing, and other industries.

Experiments on the synthesis of carboxylic acid esters have shown that it is nearly impossible to perform industrial synthesis in one stage. Furthermore, serious difficulties in isolation of the intermediate product from the first stage were encountered. Two-stage synthesis of products such as VNKh-1 inhibitor makes their industrial production considerably more expensive and lowers their competitive position in comparison with amido-imidazoline inhibitors.

It was justified in [1] that the efficiency of a hydrocarbon-soluble inhibitor is determined by:

- the electron density $(q)$ on the heteroatoms that are presumably responsible for the formation of the adsorption layer ("anchor" atoms); 
- hydrophobicity (e.g. $\pi$, the Hansch hydrophobicity constant);

- molecule size (molecular mass, molar surface or the number of water molecules $n$ displaced by the inhibitor from the metal surface upon adsorption).

It means that the degree of metal protection by an inhibitor in hydrocarbon environments is mainly a function of $\sum q, \pi$, and $n$.

Let us consider some molecular aspects of the protective action and specific behavior of hydrocarbon-soluble amides and salts of certain amines and morpholine with carboxylic acids in water-organic environments. We believe that these aspects make it possible to forecast inhibitor efficiency based on calculated physicochemical parameters using the main approaches that were employed in the development of VNKh-1 inhibitor [2].

The quantum-chemical calculations of molecular diagrams were carried out using HyperChem Version Professional Release 6.03 software from Hypercube Inc. (C) 2001 by the CNDO/2 method without optimization. Standard bond lengths and bond angles were used. The Build model was set in the Single Point mode. The molecular adsorption mechanism was simulated using the ChemBioOffice 2010 and Chem3D Pro software complex, version 12.0.2.1076.

Hydrophobicity constants $\lg P$ (Hansch $\pi$-constants) were calculated using the C. Hansch method [3, Ch. IV] based on data on the $\pi_{x}$ values of fragments, with consideration for the total fragment constants and geometrical factors. The following fragment constants were used in the calculations: $f_{\mathrm{CH}_{3}}=0.87, f_{\mathrm{CH}_{2}}^{\text {chain }}=0.63, f_{\mathrm{CH}_{2}}^{\text {ring }}=0.66$, $f_{\mathrm{CH}}=0.43, f_{\mathrm{NH}_{2}}=-1.54, f_{\mathrm{NH}}=-2.15, f_{-\mathrm{O}-}=-2.18, f_{-\mathrm{N}^{\prime}}=-1.82$ and geometrical factors $F$ characterizing the bonds and bond contributions to $\lg P$. The contribution of bonds is proportional to $n-1$, where $n$ is the number of bonds: $F_{\mathrm{b}}^{\text {chain }}=-0.12, F_{\mathrm{b}}^{\text {ring }}=-0.09$, $F_{=}^{\text {isolated }}=-0.55, \quad F_{=}^{\text {conjugated }}=-0.42, \quad F_{\mathrm{bYN}}^{\text {amine }}=-0.20$, as well as proximity factors of heteroatoms in the chain (or ring). The following fragment constants were used in the calculations of the $\pi$-constants of salts: $f_{\mathrm{CH}_{3}}=0.87, f_{\mathrm{CH}_{2}}^{\text {chain }}=0.63, f_{\mathrm{CH}_{2}}^{\text {ring }}=0.66, f_{\mathrm{CH}}=0.43$, $f_{\mathrm{CO}_{2}^{-}}=-5.19, f_{\mathrm{NH}_{3}^{+}}=-3.50$, along with geometrical factors: $F_{\mathrm{b}}^{\text {chain }}=-0.12, F_{\mathrm{b}}^{\text {ring }}=-0.09$, $F_{\mathrm{b}^{+1}}=-0.78, F_{\mathrm{b}^{+2}}=-0.40, F_{\mathrm{b}^{+3}}=-0.26, F_{\mathrm{b}^{+4}}=-0.19, F_{=}^{\text {isolated }}=-0.55$.

Let us show a full calculation of Hansch $\pi$-constant for morpholine amide with tridecanoic acid as an example:

$$
\begin{aligned}
& \overbrace{\mathrm{H}_{2} \mathrm{C}-\mathrm{CH}_{2}}^{\mathrm{H} \mathrm{C}-\mathrm{CH}_{2}} \stackrel{\mathrm{O}}{\mathrm{O}-\mathrm{C}-\left(\mathrm{CH}_{2}\right)_{11} \mathrm{CH}_{3}} \\
& \lg P=4 f_{\mathrm{CH}_{2}}+f_{-\mathrm{N}^{\prime}}+f_{-\mathrm{O}-}+f_{\mathrm{c}=\mathrm{O}}+11 f_{\mathrm{CH}_{2}}+f_{\mathrm{CH}_{3}}+(6-1) \cdot F_{\mathrm{b}}+(2-1) \cdot F_{\mathrm{b}}+(12-1) \cdot F_{\mathrm{b}}+ \\
& +F_{\mathrm{P}_{2}}+F_{=}=4 \cdot 0.66-2.18-1.82-1.90+0.87+11 \cdot 0.66+5 \cdot(-0.09)-(-0.12)+ \\
& +11 \cdot(-0.12)+0.8-0.55=2.64-2.18-1.82-1.90+0.87+7.26-0.45-0.12-1.32+ \\
& +0.8-0.55=3.23 \text {. }
\end{aligned}
$$


$F_{\mathrm{P}_{2}}$ is the proximity factor of the nitrogen-oxygen pair in the two chains of the morpholine ring.

$$
F_{\mathrm{P}_{2}}=2 \cdot(-0.1) \cdot\left(f_{-\mathbb{N}^{\prime}}+f_{-0-}\right)=2 \cdot(-0.1) \cdot(-2.18-1.82)=0.8 \text {. }
$$

Table 1 presents the main physicochemical parameters of the starting compounds used in the syntheses. Tables 2 and 3 contain the parameters of amides and salts. Designations in Tables 1-3: $q$ - electron density, $\pi$ - hydrophobicity (calculated Hansch $\pi$ constant), $\Sigma q-$ total electron density on heteroatoms, $M-$ molecular mass. The calculations were carried out for amides and salts of hexylamine, cyclohexylamine, piperidine, piperazine, and morpholine with tridecanoic acid $\mathrm{C}_{12} \mathrm{H}_{25} \mathrm{COOH}$ and oleic acid $\mathrm{CH}_{3}\left(\mathrm{CH}_{2}\right)_{7} \mathrm{CH}=\mathrm{CH}\left(\mathrm{CH}_{2}\right)_{7} \mathrm{COOH}$.

Table 1. The main physicochemical parameters of starting compounds for the synthesis of amides and salts.

\begin{tabular}{cccccc} 
Amine & $\boldsymbol{q}$ on $\mathbf{~ N}_{\mathbf{s p}^{3}}$ & $\boldsymbol{q}$ on $\mathbf{O}_{\mathbf{s p}^{3}}$ ring & $\boldsymbol{\Sigma} \boldsymbol{q}$ & $\boldsymbol{\pi}$ & $\boldsymbol{M}$ \\
\hline Hexylamine & 1.211 & - & 1.211 & 2.03 & 101 \\
Cyclohexylamine & 1.221 & - & 1.221 & 1.74 & 99 \\
Morpholine & 1.171 & 1.223 & 2.394 & -0.98 & 87 \\
Piperidine & 1.185 & - & 1.185 & 0.70 & 85 \\
Piperazine & 1.179 & - & 2.358 & -1.31 & 86 \\
\hline
\end{tabular}

It follows from the quantum-chemical calculations of molecular diagrams of the starting compounds for the synthesis of amides and salts that piperazine and morpholine have the highest metal affinity (Table 1). On the other hand, according to Hansch constants, morpholine and piperazine are hydrophilic, unlike hexylamine and cyclohexylamine. This undoubtedly affects the hydrophilic-hydrophobic balance of the derivatives, decreasing their hydrophobicity given the same chain length in the hydrophobic moiety.

In fact (Table 2), piperazine and morpholine amides are less hydrophobic than hexylamine and cyclohexylamine amides. However, as one could have expected, piperazine diamides are the most hydrophobic products among the compounds in question. Yet, the use of piperazine diamides as corrosion inhibitors is unlikely to be reasonable due to their high molecular mass and hence low solubility, even in organic media. Amides and salts of oleic acid are more hydrophobic than the corresponding amides and salts of 
tridecanoic acid. The salts are less hydrophobic than the amides of the corresponding amines and acids.

Table 2. The main physicochemical parameters of amides.

\begin{tabular}{|c|c|c|c|c|c|c|c|}
\hline Amine & Acid & $q$ on $\mathrm{N}_{\mathrm{sp}^{3}}$ & $q$ on $\mathrm{O}_{\mathrm{sp}^{3}}$ ring & $q$ on $\mathrm{O}_{\mathrm{sp}^{2}}$ & $\Sigma q$ & $\pi$ & $M$ \\
\hline Hexylamine & Tridecanoic & 1.217 & - & 1.375 & 2.592 & 7.0 & 297 \\
\hline Hexylamine & Oleic & 1.212 & - & 1.372 & 2.584 & 9.36 & 365 \\
\hline $\begin{array}{l}\text { Cyclohexyla } \\
\text { mine }\end{array}$ & Tridecanoic & 1.212 & - & 1.372 & 2.584 & 6.59 & 295 \\
\hline $\begin{array}{l}\text { Cyclohexyla } \\
\text { mine }\end{array}$ & Oleic & 1.216 & - & 1.363 & 2.579 & 8.83 & 363 \\
\hline Morpholine & Tridecanoic & 1.175 & 1.222 & 1.373 & 3.770 & 3.23 & 283 \\
\hline Morpholine & Oleic & 1.155 & 1.222 & 1.373 & 3.750 & 6.47 & 351 \\
\hline Piperidine & Tridecanoic & 1.171 & - & 1.374 & 2.545 & 4.91 & 281 \\
\hline Piperidine & Oleic & 1.165 & & 1.375 & 2.540 & 7.15 & 349 \\
\hline Piperazine & Tridecanoic & $\begin{array}{l}1.165 \\
1.177\end{array}$ & - & 1.362 & 3.704 & 3.45 & 282 \\
\hline Piperazine & $\begin{array}{c}\text { Tridecanoic } \\
\text { diamide }\end{array}$ & $\begin{array}{l}1.159 \\
1.166\end{array}$ & - & $\begin{array}{l}1.371 \\
1.372\end{array}$ & 5.068 & 8.40 & 478 \\
\hline Piperazine & Oleic & $\begin{array}{l}1.168 \\
1.172\end{array}$ & - & 1.375 & 3.715 & 5.06 & 350 \\
\hline Piperazine & $\begin{array}{c}\text { Oleic } \\
\text { diamide }\end{array}$ & $\begin{array}{l}1.158 \\
1.164\end{array}$ & - & $\begin{array}{l}1.373 \\
1.374\end{array}$ & 5.069 & 11.66 & 614 \\
\hline
\end{tabular}

Though amides of hexylamine and cyclohexylamine have high hydrophobicity, the electron density on their heteroatoms is lower than in other amides. Generally, the total electronic charge on the hetero atoms of salts is higher than that on the hetero atoms of the corresponding amides due to the presence of an additional heteroatom, namely, $\mathrm{O}_{\mathrm{sp}^{3}}$ in the salt. Products based on piperazine are an exception. The molecule sizes of all compounds within each series are rather close. As expected, piperazine diamides are an exception.

Let us consider the possible options of how hetero atom in molecules, e.g., amines, are arranged upon adsorption on a metal. When considering the options, we took into consideration the assumption [4] that adsorption of imidazolines involves the formation of a bond with the metals through the five-membered ring that is arranged in a planar way. The role of the hydrocarbon chain at position 2 consists of surface hydrophobization and creation of a barrier to corrosive components. It was assumed [4] that the hydrophilic part at position 1 of the imidazoline ring is not of primary importance for adsorption of an imidazoline molecule on a metal surface. The role of a hydrocarbon chain at position 2 consists of surface hydrophobization and creation of a barrier to corrosive components, so the inhibitor efficiency is determined by the length of the hydrophobic chain at position 2 (see Fig. 1 in [1]). 
Table 3. The main physicochemical parameters of salts.

\begin{tabular}{|c|c|c|c|c|c|c|c|c|}
\hline Amine & Acid & $q$ on $\mathrm{N}_{\mathrm{sp}^{3}}$ & $\mathrm{O}_{\mathrm{sp}^{3}}^{q^{\text {on }}}$ ring & $\begin{array}{c}q \text { on } \\
\mathrm{O}_{\mathrm{sp}^{2}} \text { salt }\end{array}$ & $\begin{array}{c}q \text { on } \\
\mathrm{O}_{\mathrm{sp}^{3}} \text { salt }\end{array}$ & $\Sigma q$ & $\pi$ & $M$ \\
\hline Hexylamine & Tridecanoic & 0.598 & - & 1.315 & 1.264 & 3.177 & 0.52 & 315 \\
\hline Hexylamine & Oleic & 0.594 & - & 1.325 & 1.281 & 3.200 & 3.63 & 383 \\
\hline $\begin{array}{l}\text { Cyclohexyla } \\
\text { mine }\end{array}$ & Tridecanoic & 0.638 & - & 1.342 & 1.307 & 3.287 & 1.21 & 313 \\
\hline $\begin{array}{l}\text { Cyclohexyla } \\
\text { mine }\end{array}$ & Oleic & 0.639 & - & 1.376 & 1.326 & 3.341 & 3.82 & 381 \\
\hline Morpholine & Tridecanoic & 0.627 & 1.218 & 1.332 & 1.344 & 4.521 & -4.60 & 301 \\
\hline Morpholine & Oleic & 0.649 & 1.219 & 1.353 & 1.372 & 4.593 & -1.24 & 369 \\
\hline Piperidine & Tridecanoic & 0.638 & - & 1.340 & 1.372 & 3.350 & -3.18 & 299 \\
\hline Piperidine & Oleic & 0.659 & - & 1.354 & 1.393 & 3.406 & -1.49 & 367 \\
\hline Piperazine & Tridecanoic & $\begin{array}{l}0.665 \\
1.174\end{array}$ & - & 1.287 & 1.341 & 4.467 & -4.86 & 300 \\
\hline Piperazine & Oleic & $\begin{array}{l}0.653 \\
1.176\end{array}$ & - & 1.306 & 1.374 & 4.509 & -4.49 & 368 \\
\hline
\end{tabular}

Let us consider hypothetical adsorption schemes of fatty acid amides and a cyclohexylamine - fatty acid salt (Fig. 1). Amides and a salt of saturated tridecanoic acid are considered in the scheme. Let us analyze the hypothetical adsorption schemes with consideration for the data in Tables $1-3$ and the possible inhibiting efficiency of the products. The adsorption of hexylamine, cyclohexylamine, and piperidine amides presumably involves two heteroatoms, whereas the adsorption of the other amides (and the cyclohexylamine salt) involves three heteroatoms.

Comparison of hexylamine and cyclohexylamine amides (with nearly equal electronic charges on the heteroatoms which are presumably responsible for adsorption) indicates that cyclohexylamine amide is less hydrophobic. It may be assumed that its efficiency under comparable conditions will be lower.

Similar values for piperidine, piperazine and morpholine amides are much smaller. However, piperazine and morpholine amides characterized by low hydrophobicity have high electron density on the heteroatoms that allows one to assume that their adsorption is higher. However, their efficiency can be equal (or somewhat lower) than that of piperidine, hexylamine, and cyclohexylamine amides. The cyclohexylamine salt occupies a special place, both based on the hypothetical adsorption scheme (involving three atoms on the assumption of hydrolysis) and taking the low hydrophobicity constant into account. 
Hexylamine amide adsorption

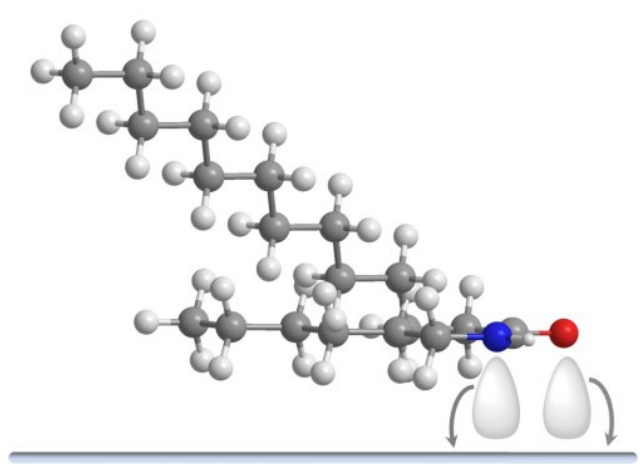

Cyclohexylamine salt adsorption

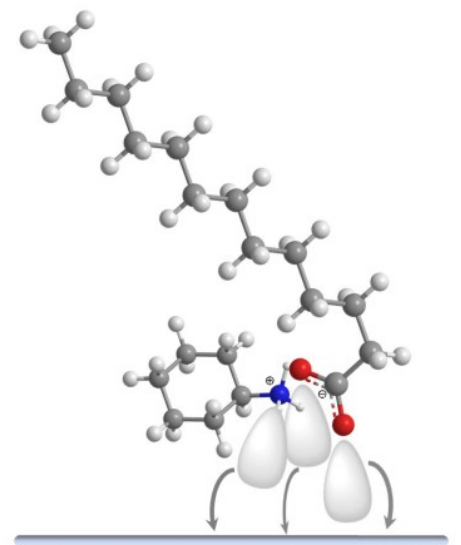

Piperazine amide adsorption

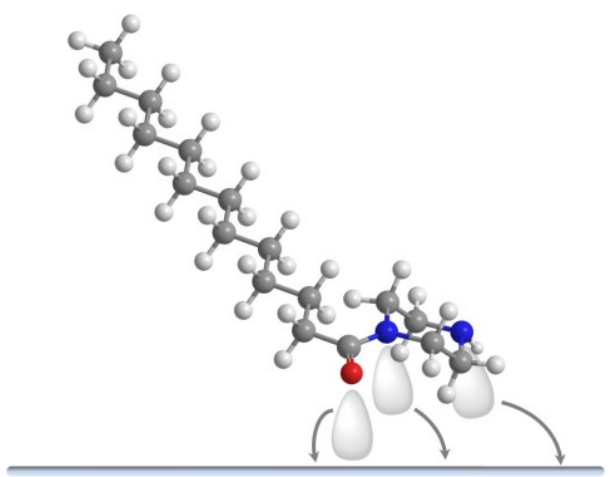

Cyclohexylamine amide adsorption

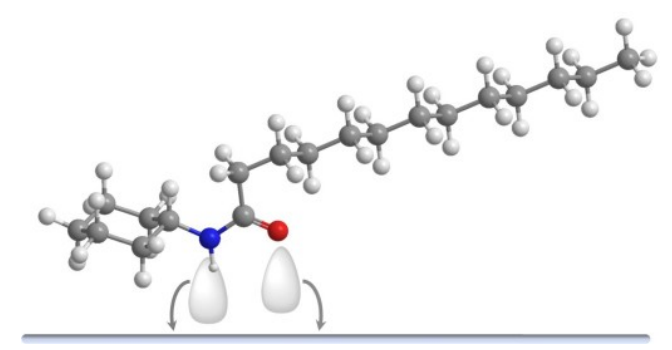

Piperidine amide adsorption

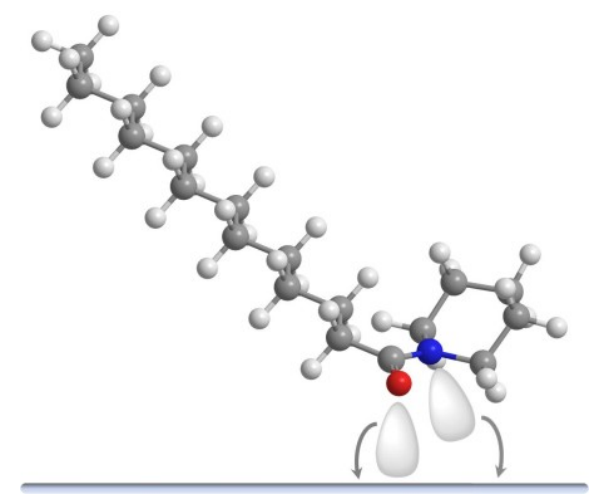

Morpholine amide adsorption

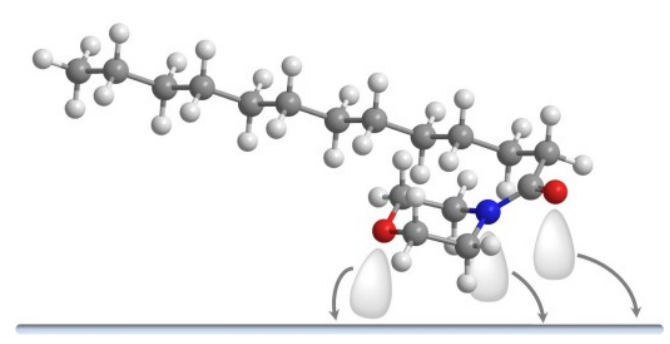

Figure 1. Hypothetical adsorption schemes of fatty acid amides and a salt of cyclohexylamine with a fatty acid.

In our next communication we are going to analyze from this point of view the data of corrosion tests and electrochemical studies on the degree of adsorption and efficiency based on polarization curves and compare the conclusions with those made using the hypothetical adsorption schemes. 


\section{Conclusions}

1. Aspects of the relationship between the physicochemical and electronic characteristics of inhibitors that allow one to forecast the efficiency of metal corrosion inhibitors in water-hydrocarbon media are considered.

2. An approach based on thermodynamic analysis of the surface activity criteria of organic compounds and estimation of their affinity to a metal ("metallophilicity") based on electronic structure was used to choose the starting compounds and reactions for synthesizing new hydrocarbon soluble corrosion inhibitors.

3. It has been substantiated how the inhibitor efficiency in water-hydrocarbon environments depends on the electron density on the molecule heteroatoms presumably responsible for the formation of the adsorption layer ("anchor" atoms), hydrophobicity (Hansch hydrophobicity $\pi$-constants), and molecule size.

4. Hypothetical adsorption models have been suggested for tridecanoic acid amides with hexylamine, cyclohexylamine, piperidine, piperazine, morpholine and the cyclohexylamine quaternary salt.

5. The hypothetical adsorption schemes and the possible inhibitor efficiency of the products were analyzed with consideration for data on electronic charges and hydrophobicity of the molecules.

\section{References}

1. A. I. Altsybeeva, V. V. Burlov, E. A. Tronova, T. M. Kuzinova and G. F. Palatik, Int. J. Corros. and Scale Inhib., 2014, 3, no. 1, 66. doi: 10.17675/2305-6894-2014-3-1-066077

2. A. I. Altsybeeva, T. M. Kuzinova and E. M. Agres, Zashch. Met., 2003, 39, no. 3, 1 (in Russian).

3. C. Hansch and A. Leo, Substituent Constants for Correlation Analysis in Chemistry and Biology, New York, Wiley, 1981.

4. A. Edwards, C. Osborne, S. Webster, D. Klenerman, M. Joseph, P. Ostovar and M. Doyle, Corros. Sci., 1994, 36, no. 2, 315. 